\title{
Computational and Molecular Characterization of Surface Proteins Neuraminidase and Haemagglutinin from Egyptian Isolates of Avian Influenza H5N1 Subtype
}

\author{
Soliman YA ${ }^{1 *}$, Maha AN Gamal ${ }^{\mathbf{1}}$ and Eman MS El-Nagar ${ }^{\mathbf{2}}$ \\ ${ }^{1}$ ARC, Central Laboratory for Evaluation of Veterinary Biologics, Abassia, Cairo, Egypt \\ ${ }^{2} A R C$, Veterinary Serum and vaccine research institute, Abassia, Cairo, Egypt \\ *Corresponding Author: Soliman YA, ARC, Central Laboratory for Evaluation of \\ Veterinary Biologics, Abassia, Cairo, Egypt.
}

\author{
Received: April 16, 2020 \\ Published: April 29, 2020 \\ (C) All rights are reserved by Soliman YA., \\ et al.
}

\begin{abstract}
Avian influenza isolated from different Egyptian governorate during the period of 2010-2017 have been computationally evaluated for the B-cell and T-cell epitope mapping and MHC II binding sequence prediction. The ten studied isolates showed limited variation on the level of deduced amino acid for the N1 gene, on the other hand H5 gene showed much wider variation. Many B - and T- cell epitopes have been predicted for both H5 and N1 proteins which spanning nearly the entire sequence. B- Cell epitopes have been seen within the cleavage site thus the generated antibody clone might hinder the cleavage of haemagglutinin by the cellular protease and prevent viral entry. Different T- cell epitopes found on the N1 protein can stimulate IFN- $\gamma$ production and hence inhibit viral replication. These data explain the power of genetic vaccine coding for both H5 and N1 to elucidate high protection rate with minimal shedding level.
\end{abstract}

Keywords: Avian Influenza; Haemagglutinin Gene; Neuraminidase Gene; Highly Pathogenic; Cleavage Site

\section{Introduction}

A recent strain of influenza, the highly pathogenic avian influenza (HPAI) H5N1, and its variants have been in circulation since the first major outbreak in 1997 among birds in South East Asia leading to many human deaths [1]. High mutation rate and wide variety of birds and mammals including human hosts are probable reasons of pandemic-causing ability of the virus. Previous studies on the pathogenicity of influenza virus have reported the role of different kinds of genetic events like antigenic shift, antigenic drift, recombination and reassortment as major reasons for the emergence of virulent strains.

Protection against infection with avian influenza is greatly based on the antibody mediated neutralization of the viral cell entry glycoprotein receptor (the haemagglutinin receptor) that hinder virus attachment with the sialic acid $\alpha-2,3$ or $\alpha-2,6$ galactose receptor on mammalian cell surface and prevents the first step in viral infection [2]. Also, it will hinder the final release of the replicating virus from infected cells throw neutralization of the release protein (neuraminidase receptor) [3].

IFN- $\gamma$ plays a crucial role in the transcription inhibition of the viral genome within the infected cells [4]. Influenza virus there- fore is equipped with transcriptional machinery that is not proof reading which facilitates the rapid mutations of the virus receptors enabling it to escape such neutralization effect. A DNA vaccine coding for the HA and NA protein antigens have been developed by our team based on either the HA or NA of the HPAI H5N1 subtype. In order to maintain the DNA vaccine efficacy with the periodic antigenic drift, one must keep up tracing the newly emerging strains and testing them using the traditional $\mathrm{HI}$ assay of in vivo challenge so. These methods are time consuming and work labor.

The proteins resides antigenicity in different types of antigenic determinants known as epitopes, different types of epitopes have been recognized including continuous, discontinuous, neotopes, cryptotopes and mimotopes. All have fuzzy boundaries and can be identified only by their binding abilities to the corresponding antibodies. Because the antibodies are able to recognize a considerable number of related epitopes, thus the antigenic cross-reactivity will be a common phenomenon.

$\mathrm{T}$ cell immunity has been implicated in rapid clearance of influenza virus [2] that is reflected in decreased fatality and less spread of the virus in population. Therefore, a vaccine generating robust $\mathrm{T}$ cell immunity against influenza needs serious attention. Good $\mathrm{T}$ 
Computational and Molecular Characterization of Surface Proteins Neuraminidase and Haemagglutinin from Egyptian Isolates of Avian Influenza H5N1 Subtype

cell immunity along with antibody response focused on receptor binding region of the hemagglutinin protein and enzymatic active site of neuraminidase, would meet the needs of a universal vaccine. Especially the internal proteins contain many conserved peptides which are potential $\mathrm{T}$ cell antigens and hence need serious consideration as $\mathrm{T}$ cell focused vaccine candidates.

In this study, we have computationally analyzed the deduced amino acid sequences of H5N1 influenza A subtype (Egyptian isolates) to identify putative B- and T- cell epitopes and MHC II binding.

\section{Materials and Methods}

Virus

A total of 10 highly pathogenic avian influenza virus H5N1 subtypes have been isolated in Egypt (Table 1) during the years 20102017, the isolates were previously identified by HA and HI, RT-PCR sequencing [5-7]. The isolates were propagated on embryonated chicken eggs via the allantoic route. The allantoic fluid was collected and purified by centrifugation at $14000 \mathrm{rpm} / 10 \mathrm{~min} / 4^{\circ} \mathrm{C}$.

\begin{tabular}{|l|c|c|c|c|}
\hline \multicolumn{1}{|c|}{ Sample ID } & Virus mane & Year of sampling & Breed of the birds & Province \\
\hline CLEVB.4.2011 & A/chicken/ Kalyobia /ch.4.3/2011(H5N1) & Mar 2011 & Cobb & Kalyobia \\
\hline CLEVB.5.2011 & A/chicken/ Kalyobia /ch.5.12/2011(H5N1) & Dec.2011 & Baladi & Kalyobia \\
\hline CLEVB.7.2011 & A/chicken/ Sharkia /ch.7.1/2011(H5N1) & Jan.2011 & White Lohmann & Sharkia \\
\hline CLEVB.2.2010 & A/chicken/ Kalyobia /ch.2.1/2010(H5N1) & Jan.2010 & Cobb & Kalyobia \\
\hline CLEVB.18.2012 & A/chicken/ Mansoura /ch.18.2/2012(H5N1) & Feb.2012 & Arbo & Mansoura \\
\hline CLEVB.6.2013 & A/chicken/ Kalyobia /ch.6.1/2013(H5N1) & Jan.2013 & White Lohmann & Kalyobia \\
\hline CLEVB.5.2014 & A/chicken/ Mansoura /ch.5.2/2014(H5N1) & Feb.2014 & White Lohmann & Mansoura \\
\hline CLEVB.10.2015 & A/chicken/ Gharbia /ch.10.1/2015(H5N1) & Jan.2015 & Cobb & Gharbia \\
\hline CLEVB.22.2017 & A/chicken/ Kalyobia /ch.22.1/2017(H5N1) & Jan.2017 & Cobb & Kalyobia \\
\hline CLEVB.11.2017 & A/chicken/ Sharkia /ch.11.3/2017(H5N1) & Mar.2017 & White Lohmann & Sharkia \\
\hline
\end{tabular}

Table 1: The H5N1 viruses used in this study with the date and province of isolation.

Amplification of the full length H5 and N1 genes of the H5N1 isolates by RT-PCR amplification

Viral RNA was extracted from the clarified Allantoic fluid [8], by QIAamp Viral RNA Mini Kit (Qiagen Germany, cat \#52904), according to the manufacturer's instructions.

The full length H5 and N1 genes of the H5N1 isolate were amplified by two steps RT-PCR. First, the cDNA was synthesized using M-MuLV First Strand cDNA Synthesis Kit (Biomatik cat \# K5147) according to the manufacture instruction. Briefly $5 \mu \mathrm{l}$ of the viral RNA was incubated at $65^{\circ} \mathrm{C} / 5 \mathrm{~min}$ with $100 \mathrm{nM}$ of each sense primer and $1 \mu \mathrm{l}$ of dNTP (10 mmole each) in a volume of $14.5 \mu \mathrm{l}$. The mixture was then incubated on ice/5 min then $1 \mu \mathrm{l}$ of $5 \mathrm{X}$ RT buffer, 40 IU of RNase inhibitor and 200 IU of M-MuLV reverse transcriptase enzyme was added. The reactions were incubated at $25^{\circ} \mathrm{C} / 5 \mathrm{~min}$ then at $42^{\circ} \mathrm{C} / 60 \mathrm{~min}$. the reverse transcriptase was deactivated by incubation at $85^{\circ} \mathrm{C} / 5 \mathrm{~min}$.

Second step PCR was done using Pfu Ultra II Hotstart PCR Master Mix (Agilent USA cat \# 600850). Fife microliter of the cDNA were included in each reaction using 50 pMole of primers that amplify the full orf of H5 H5-f ATGGAGAAAATAGTGCTTCTTCTT and H5-r AATGCAAATTCTGCATTGTAACGA and N1 genes N1-f AGCAAAAGCAGGAGGTTAAAAGGA and N1-r TAGCAACAAGGAGGTTTTTGAACAACC The primers were designed and verified by Lasergene DNAStare software V 15. The primers were Sensitized by Bio Basic Inc. (Canada), purified by HPLC and concentrated to $100 \mu \mathrm{Mol}$. The amplicons were electrophoresed on a $1 \%$ agarose and the size of the amplicons were determine using SynGene tool software V4.01 (SynGen Corporation, Cambridge, England).

\section{Sequencing}

The complete nucleotide sequences of the full lengthy H5 and $\mathrm{N} 1$ of the 20 isolated strains were performed in (Macrogen USA). For preparation of the gene for sequencing, the PCR product was separated on $1 \%$ low melting agarose. The bands were sliced off and purified with the biospin PCR purification kit (Biobasic cat \# BSC03S1) as described by the manufacture. Sequencing reactions were performed in a MJ Research PTC-225 Peltier Thermal Cycler using ABI PRISM 3730XL Analyzer BigDyeTM Terminator Cycle Sequencing Kits with AmpliTaq DNA polymerase (FS enzyme Applied Biosystems), following the protocols supplied by the manufacturer. Single-pass sequencing was performed on each template using the primer used for PCR amplification. The fluorescent-labeled frag- 
ments were purified from the unincorporated terminators with an ethanol precipitation protocol. The samples were resuspended in distilled water and subjected to electrophoresis in an ABI 3730xl sequencer (Applied Biosystems).

\section{Phylogenetic analysis}

All the sequences were aligned with ClustalW using DNAStare software V15. The computed alignment was manually checked and corrected. Pair-wise evolutionary distances were computed using the ClustalW implemented in the DNAStare V15 program and a phylogenetic tree was constructed by neighbor-joining method which comprise DNA weight matrix for nucleotide. Bootstrapped values of 1000 were sampled to determine a measure of support for each node on the consensus tree.

Prediction and identification of B- cell, T-cell and MHC epitopes

Structure analysis of both consensus H5 and N1 deduced amino acid were done using Swiss modeling software, epitope mapping were done using protein D module od DNAStare V15 software.

\section{Prediction of MHC II binding sequence}

The MHC-II binding predictions were made on 4/15/2020 using the IEDB analysis resource Consensus tool $[9,10]$.

\section{Results}

Reverse transcriptase polymerase chain reaction (RT-PCR)

SPF eggs were inoculated with the H5N1 isolates listed in table 1 embryos were died within $24 \mathrm{~h}$ and gave positive HA and HI, full length $\mathrm{H} 5$ and the $\mathrm{N} 1$ genes were amplified from the 10 isolates of HPAI H5N1 subtype, clear visible band with molecular size of $1700 \mathrm{bp}$ and $1400 \mathrm{bp}$ for the full length $\mathrm{H} 5$ and N1 genes respectively.

\section{Sequencing analysis of the $\mathrm{H} 5$ and $\mathrm{N} 1$ genes}

The nucleotide sequence and the deduced amino acid sequences of the neuraminidase gene $\mathrm{N} 1$ of 10 isolates were aligned using MegAlin suit of the DNAStare V15 software, as seen in figure 1, few point mutations were seen between the isolates these mutations were mostly substitution mutations and resulted in changes in the amino acid sequence. Cladogram created by CLASTALW with bootstrapping of 1000 (Figure 2A) revealed that strains CLEVB.5.2011, CLEVB.5.2014 and CLEVB.11.2017 were grouped together while the most distance isolates were CLEVB.10.2015 and CLEVB.4 these findings revealed two strains have isolated in year 2011 (strain 4, 5 and 7 ) were having much distance $(0.38$ and 0.39 with strain 5 and 7 respectively) these data denotes that many circulating sub-strains may be found (Table 2). Concerning the haemagglutination genes H5, found to possess more mutation (mostly substitutions. Phylogenetic tree (Figure 2B) revealed that H5 showed more diverse changes than N1 gene. The isolates were clustered into 3 groups, the first group contain 3 isolates (CLEVB.18.2012, 11.2017 and 5.2014) and the second group contain on isolate (CLEVB.5.2011) that is widely separated (overall amino acid substitutions of 0.135 ) and the remaining isolates were grouped together in the $3^{\text {rd }}$ group. The distance matrix (Table 3) showed more heterogeneity between the isolates.

\section{Structure analysis $\mathrm{H} 5$ and $\mathrm{N} 1$ protein antigen}

The consensus sequence of the deduced amino acid were subjected to structure modulation using Swiss structure modeling tool. As seen in figure $3 \mathrm{~A}$, the protein is composed of 4 identical units (Homo tetramer) and have a global shape, Ramachandran plot revealed that the structure is mostly beta sheeted with view wright handed alpha helices. On the other hand, the haemagglutinin protein is homo-trimeric molecules (Figure 3B) with excessive beta sheeted structure and coils (Figure 3 and 4).

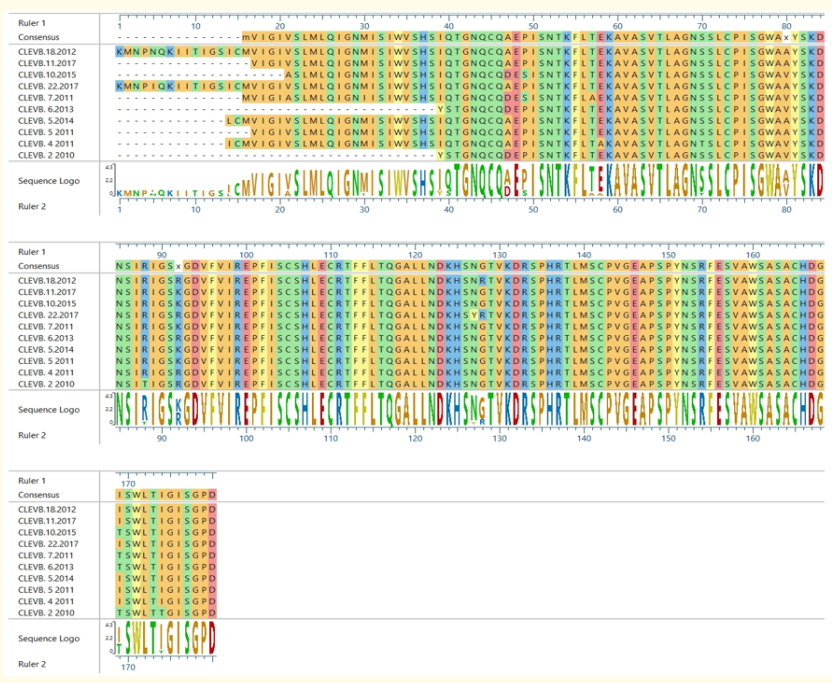

Figure 1: Alignment comparison of the deduced amino sequences of the full length $\mathrm{N} 1$ gene of the 10 Egyptian isolated.

Epitope mapping of $\mathrm{H} 5$ and $\mathrm{N} 1$ protein antigen

The consensus deduce amino acid sequence was mapped against both T- and B- cell epitopes, for the haemagglutinin gene, at least 8 areas with high threshold were predicted to contain $\mathrm{T}$ cell epitopes (Figure 5) with hydrophobicity threshold over 1.5 (as measure by Foucher piska method). For the neuraminidase gene however, fewer areas were predicted surprisingly but the fact that $\mathrm{N} 1$ protein is tetrameric molecules, the antigenicity would be much higher than the $\mathrm{H} 5$ which is trimeric molecule. Concerning B cell epitopes, it was found that both antigens containing many epitopes covering nearly the entire molecules. But the most important areas were the epitopes at the cleavage site of the H5 antigens and at the global head of the $\mathrm{N} 1$ protein were the enzymatic dome is contained. 

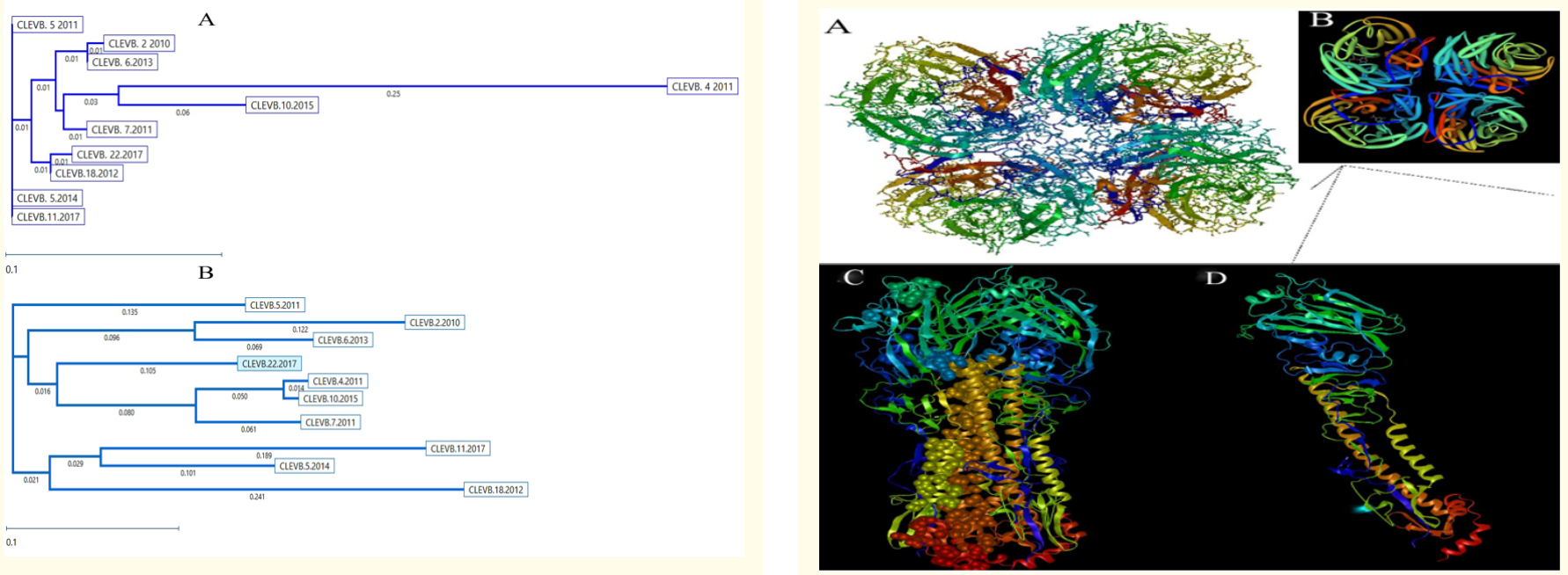

Figure 2: IPhylogenic tree analysis of the N1 gene (A) and H5 gene (B) for the 10 HPAI H5N1 viruses. Nucleotide sequences were analyzed and the deduced amino acid was created using DNAStare V15 and alignment was created using CLSTALW method. The lengths of the horizontal lines are proportional to the minimum number of amino acid differences required to join the nodes. Numbers at the nodes indicate confidence levels of bootstrap analysis with 1000 replications.

A

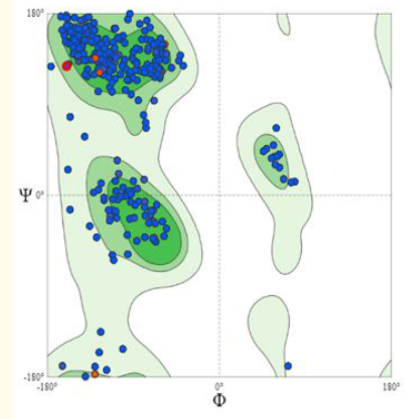

B

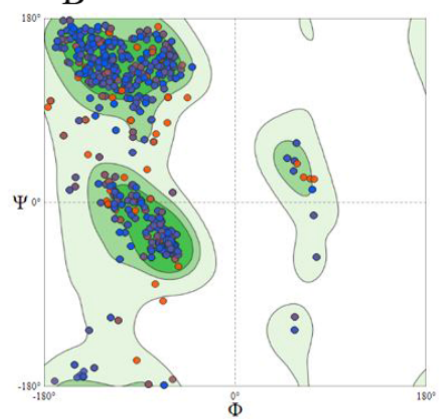

Figure 4: The Ramachandran plot of the consensus deduced amino sequence of neuraminidase (A) and haemagglutinin (B) showing the majority of the structure is beta sheeted and right angled alpha helices.

Figure 3: The structure of homotetramer molecule of N1 as peridected by swess module (A) rabon like and (B) the tube like, and the homotrimer (C) and monomeric molecule (D) of heamagglutinin gene (H5). the structure showing both beta sheted and alpha helecies structure of $\mathrm{N} 1$ gene.

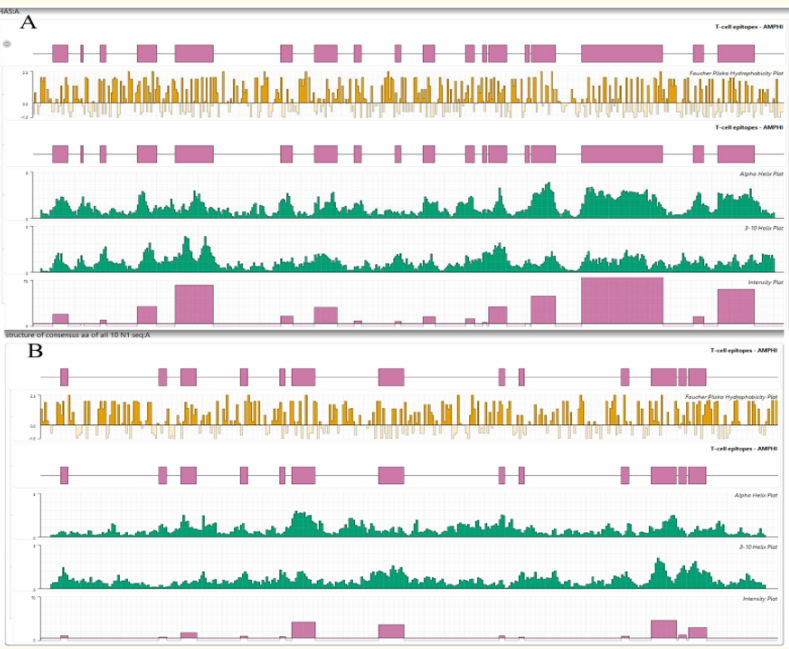

Figure 5: T cell epitope and hydrophobicity plot of the H5 protein antigen (A) and N1 protein antigen (B).

\begin{tabular}{|l|c|c|c|c|c|c|c|c|c|c|c|}
\hline & A & B & C & D & E & F & G & H & I & J \\
\hline A & CLEVB.18.2012 & & 0.02 & 0.12 & 0.01 & 0.04 & 0.03 & 0.02 & 0.02 & 0.38 & 0.04 \\
\hline B & CLEVB.11.2017 & 0.02 & & 0.12 & 0.03 & 0.03 & 0.04 & 0.00 & 0.00 & 0.38 & 0.04 \\
\hline C & CLEVB.10.2015 & 0.12 & 0.12 & & 0.13 & 0.10 & 0.12 & 0.12 & 0.12 & 0.41 & 0.12 \\
\hline D & CLEVB. 22.2017 & 0.01 & 0.03 & 0.13 & & 0.05 & 0.04 & 0.03 & 0.03 & 0.40 & 0.05 \\
\hline E & CLEVB. 7.2011 & 0.04 & 0.03 & 0.10 & 0.05 & & 0.03 & 0.03 & 0.03 & 0.39 & 0.04 \\
\hline F & CLEVB. 6.2013 & 0.03 & 0.04 & 0.12 & 0.04 & 0.03 & & 0.04 & 0.04 & 0.39 & 0.01 \\
\hline G & CLEVB. 5.2014 & 0.02 & 0.00 & 0.12 & 0.03 & 0.03 & 0.04 & & 0.00 & 0.38 & 0.04 \\
\hline H & CLEVB. 5.2011 & 0.02 & 0.00 & 0.12 & 0.03 & 0.03 & 0.04 & 0.00 & & 0.38 & 0.04 \\
\hline I & CLEVB.4.2011 & 0.38 & 0.38 & 0.41 & 0.40 & 0.39 & 0.39 & 0.38 & 0.38 & & 0.40 \\
\hline J & CLEVB.2.2010 & 0.04 & 0.04 & 0.12 & 0.05 & 0.04 & 0.01 & 0.04 & 0.04 & 0.40 & \\
\hline
\end{tabular}

Table 2: The similarity index of the N1 deduce amino acid sequence alignment of the 10 isolates of avian influenza H5N1 subtype. 


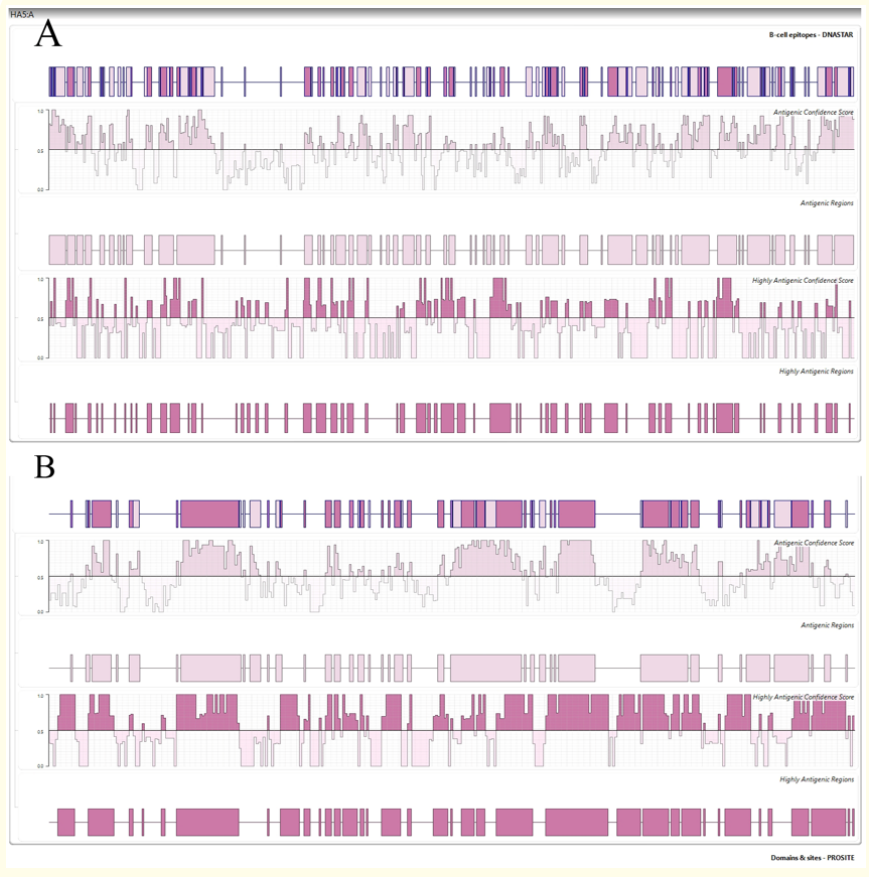

Figure 6: B cell epitope and hydrophobicity plot of the H5 protein antigen $(\mathrm{A})$ and $\mathrm{N} 1$ protein antigen $(\mathrm{B})$.
MHC II prediction of $\mathrm{H} 5$ and $\mathrm{N} 1$ protein antigen

Prediction of the MHC II sequence have been created using online IEDB-analysis tool (http://tools.immuneepitope.org/main/). About 24 predicted sequence with percentile rank $>95$ have been addressed for the haemagglutinin gene and 21 predicted sequence with percentile rank over 90 addressed for the neuraminidase gene 9 (Table 4) covering nearly the entire protein.

\section{Discussion}

Haemagglutinin and neuraminidase antigens consider to be the most important antigens regarding viral entry and shedding. DNA vaccine coding for both antigens will be a good alternative to the commercially available inactivated vaccine for its lower cost in production and the ease of update to the circulating field strains. Several previous studies showed that the DNA vaccine coding for both $\mathrm{H} 5$ and N1 genes elucidated protection rate up to $92 \%$ with nearly zero shedding [5-7]. To ensure the effectiveness of the DNA vaccine, one must investigate the circulating strain regarding to the cross reactivity with the vaccine which might me time consuming and work labor. Computational analysis of the isolates would be a best alternative.

\begin{tabular}{|c|c|c|c|c|c|c|c|c|c|c|c|}
\hline \multicolumn{2}{|c|}{ El Distance } & \multicolumn{9}{c|}{ Metric: Uncorrected Pairwise Distance } & Sequences: 10 \\
\hline & & $\mathrm{A}$ & $\mathrm{B}$ & $\mathrm{C}$ & $\mathrm{D}$ & $\mathrm{E}$ & $\mathrm{F}$ & $\mathrm{G}$ & $\mathrm{H}$ & $\mathrm{I}$ & $\mathrm{J}$ \\
\hline A & CLEVB.7.2011 & & 0.34 & 0.29 & 0.12 & 0.30 & 0.12 & 0.48 & 0.24 & 0.33 & 0.40 \\
\hline B & CLEVB.5.2014 & 0.34 & & 0.29 & 0.32 & 0.34 & 0.34 & 0.36 & 0.24 & 0.39 & 0.29 \\
\hline C & CLEVB.5.2011 & 0.29 & 0.29 & & 0.27 & 0.31 & 0.27 & 0.39 & 0.27 & 0.39 & 0.37 \\
\hline D & CLEVB.10.2015 & 0.12 & 0.32 & 0.27 & & 0.31 & 0.02 & 0.47 & 0.24 & 0.35 & 0.41 \\
\hline E & CLEVB.6.2013 & 0.30 & 0.34 & 0.31 & 0.31 & & 0.31 & 0.40 & 0.31 & 0.19 & 0.39 \\
\hline F & CLEVB.4.2011 & 0.12 & 0.34 & 0.27 & 0.02 & 0.31 & & 0.48 & 0.25 & 0.34 & 0.43 \\
\hline G & CLEVB.18.2012 & 0.48 & 0.36 & 0.39 & 0.47 & 0.40 & 0.48 & & 0.40 & 0.47 & 0.48 \\
\hline H & CLEVB.22.2017 & 0.24 & 0.24 & 0.27 & 0.24 & 0.31 & 0.25 & 0.40 & & 0.37 & 0.37 \\
\hline I & CLEVB.2.2010 & 0.33 & 0.39 & 0.39 & 0.35 & 0.19 & 0.34 & 0.47 & 0.37 & & 0.40 \\
\hline J & CLEVB.11.2017 & 0.40 & 0.29 & 0.37 & 0.41 & 0.39 & 0.43 & 0.48 & 0.37 & 0.40 & \\
\hline
\end{tabular}

Table 3: The similarity index of the H5 deduce amino acid sequence alignment of the 10 isolates of avian influenza H5N1 subtype.

All of the ten H5N1 isolates from Egypt belongs to the highly pathogenic $\mathrm{AI}$ as they contained the amino acid sequence PQGE(R/ G/K)RRKKR $\downarrow$ GL For the cleavage site in the HA molecule, indicating their high virulence [11]. This cleavage sequence was slightly differ from that of A/Hong Kong/156/97(H5N1) virus PQRERRRKKR ${ }^{\downarrow} G$ as the $3^{\text {rd }}$ amino acid was substituted from $\mathrm{R}$ in Hong Kong strains to $G$ in the Egyptian strains and also the $5^{\text {th }}$ amino acid was $R$ in all Hong Kong strains but it was either R, G or $\mathrm{K}$ in the Egyptian strains [12]. Cleavage of the HA molecule $\left(\mathrm{HA}_{0}\right)$, by host-cell proteases, into two disulphide-linked $\mathrm{HA}_{1}$ and $\mathrm{HA}_{2}$ subunits is essential for viral infectivity. Avian influenza viruses with high and low levels of pathogenicity differ in their cleavage sequence, the former possess multiple basic amino acid residues, while the latter do not. A cleavage sequence containing several basic amino acids is more readily activated by cellular proteases present in a variety of cells distributed throughout the body compared with a cleavage sequence containing only a single basic amino acid, which can be cleaved by a limited range of cellular proteases. It is well accepted that influenza viruses containing multiple basic amino acids have multiple sites of virus replication and produce more severe infection in birds and mammals [13]. B and T cell epitope mapping revealed that many predicted epitope were found spanning this polybasic motifs thus, the DNA vaccine coding for both $\mathrm{H} 5$ will be able to induce the production of antibody clones that block the cleavage process rendering the virus unable to cell entry and hence reduce the infection [5]. 


\begin{tabular}{|c|c|c|c|c|c|c|c|}
\hline \multicolumn{8}{|c|}{ MHC II prediction for $\mathrm{H} 5$ and $\mathrm{N} 1$ protein antigens } \\
\hline Start & End & Sequence & Rank & Start & End & Sequence & Rank \\
\hline \multicolumn{4}{|c|}{ Haemagglutination protein antigen } & \multicolumn{4}{|c|}{ Neuraminidase Protein Antigen } \\
\hline 290 & 304 & NTKCQTPIGAINSSM & 95.28 & 289 & 303 & GDNPRPNDGTGSCGP & 99.56 \\
\hline 334 & 348 & NSPQREKRRKKRGLF & 94.79 & 290 & 304 & DNPRPNDGTGSCGPV & 99.51 \\
\hline 226 & 240 & PKIATRSKVNGQSGR & 94.72 & 292 & 306 & PRPNDGTGSCGPVSP & 99.37 \\
\hline 227 & 241 & KIATRSKVNGQSGRM & 94.58 & 293 & 307 & RPNDGTGSCGPVSPN & 99.34 \\
\hline 51 & 65 & KTHNGKLCNLDGVKP & 94.38 & 288 & 302 & FGDNPRPNDGTGSCG & 99.31 \\
\hline 291 & 305 & TKCQTPIGAINSSMP & 94.32 & 291 & 305 & NPRPNDGTGSCGPVS & 99.22 \\
\hline 333 & 347 & RNSPQREKRRKKRGL & 94.27 & 294 & 308 & PNDGTGSCGPVSPNG & 99.16 \\
\hline 289 & 303 & CNTKCQTPIGAINSS & 94.14 & 287 & 301 & VFGDNPRPNDGTGSC & 98.76 \\
\hline 285 & 299 & EYSNCNTKCQTPIGA & 94.07 & 108 & 122 & DKHSNGTVKDRSPHR & 98.25 \\
\hline 335 & 349 & SPQREKRRKKRGLFG & 93.92 & 295 & 309 & NDGTGSCGPVSPNGA & 97.78 \\
\hline 269 & 283 & YKIVKKGDSTIMKSE & 93.35 & 107 & 121 & NDKHSNGTVKDRSPH & 97.67 \\
\hline 136 & 150 & DSWSDHETSGVSSAC & 93.34 & 340 & 354 & IWDPNGWTGTDSSFS & 97.65 \\
\hline 190 & 204 & LWGIHHPNDAAEQTR & 93.25 & 394 & 408 & RGRPKESTIWTSGSS & 97.3 \\
\hline 288 & 302 & NCNTKCQTPIGAINS & 93.14 & 248 & 262 & YPDAGEITCVCRDNW & 97.29 \\
\hline 225 & 239 & VPKIATRSKVNGQSG & 93 & 286 & 300 & GVFGDNPRPNDGTGS & 97.22 \\
\hline 139 & 153 & SDHETSGVSSACPYQ & 92.42 & 235 & 249 & LDAPNYHYEECSCYP & 97.06 \\
\hline 140 & 154 & DHETSGVSSACPYQG & 92.38 & 249 & 263 & PDAGEITCVCRDNWH & 96.99 \\
\hline 287 & 301 & SNCNTKCQTPIGAIN & 92 & 236 & 250 & DAPNYHYEECSCYPD & 96.78 \\
\hline 137 & 151 & SWSDHETSGVSSACP & 91.91 & 109 & 123 & KHSNGTVKDRSPHRT & 96.55 \\
\hline 419 & 433 & ERRIENLNKKMEDGF & 91.52 & 234 & 248 & ELDAPNYHYEECSCY & 96.37 \\
\hline 382 & 396 & DKESTQRAIDGVTNK & 91.28 & 285 & 299 & SGVFGDNPRPNDGTG & 96.35 \\
\hline 332 & 346 & LRNSPQREKRRKKRG & 91.27 & & & & \\
\hline 383 & 397 & KESTQRAIDGVTNKV & 91.09 & & & & \\
\hline 284 & 298 & LEYSNCNTKCQTPIG & 91.03 & & & & \\
\hline
\end{tabular}

Table 4: MHC II prediction for both H5 and N1 protein antigens.

MHCII prediction revealed many sequence that can bind directly to this receptor in both $\mathrm{H} 5$ and N1, these epitopes have high binding affinity to MHC II that be able to cope with the challenge of antigenic drift [14].

Also the presence of multiple B-cell epitopes at the globular head where the enzymatic activity of $\mathrm{N} 1$ protein antigen is located [15] will render the virus unable to release from the infected cells after viral assembly, these data explain the low shedding level obtained after DNA vaccination with DNA vaccine coding for N1 gene [16]. for these reasons we can consider the importance of using genetic vaccines, like DNA vaccine to obtain a high protection level with minimal shedding [5,6] and finally easly to be updated by computational prediction.

\section{Conclusion}

In conclusion, B- and T- cell epitope mapping have been addressed to the $\mathrm{H} 5$ and N1 protein antigens for the Egyptian isolates from 2010 - 2017. Enabling the study of any emerging strain of avian influenza and computationally judge the capability of the vaccine to exhibit cross protection.

\section{Funding Sources}

This research did not receive any specific grant from funding agencies in the public, commercial, or not-for-profit sectors.

\section{Conflicts of Interest}

The authors declare that there are no conflicts of interest. 


\section{Ethical Statement}

All applicable international, national and/or institutional guidelines for the care and use of animals were followed. This article does not contain any studies with human participants performed by any of the authors.

\section{Bibliography}

1. Kruy SL Buisson and Y Buchy P. "Asia: avian influenza H5N1". Bulletin de la Société de Pathologie Exotique 101 (2008): 238242.

2. Wan H and Perez DR. "Quail carry sialic acid receptors compatible with binding of avian and human influenza viruses". Virology 346 (2006): 278-286.

3. Luke CJ and Subbarao K. "Vaccines for pandemic influenza". Emerging Infectious Diseases 12 (2006): 66-72.

4. Santhakumar D., et al. "Avian Interferons and Their Antiviral Effectors". Frontiers in Immunology 8 (2017): 49-66.

5. Eman MS El-Nagar. "Study of the immune potentiation effect of Esat- 6 of Mycobacteria on DNA vaccine encoding the H5 gene of avian influenza virus". PhD thesis, Faculty of Veterinary Medicine, Cairo University (2014).

6. Maha AN Gamal. "Production and Evaluation of DNA vaccine coding for Neuraminidase N1 gene against avian influenza H5N1". PhD thesis, Faculty of Veterinary Medicine, Alexandria University (2016).

7. Soliman YA., et al. "Generation of Plasmid Vector Coding for Neuraminidase Gene NA1 of Highly Pathogenic Avian Influenza H5N1 Subtype". Alexandria Journal of Veterinary Sciences 51.2 (2016): 101-111.

8. Sambrook J., et al. "Molecular cloning. A Laboratory Manual, $2^{\text {nd }}$ Edition, Cold Spring Harbor Lab. N.Y (1989).

9. Wang P., et al. "Peptide binding predictions for HLA DR, DP and DQ molecules". BMC Bioinformatics 11 (2010): 568-575.

10. Wang P., et al. "A systematic assessment of MHC class II peptide binding predictions and evaluation of a consensus approach". PLOS Computational Biology 4.4 (2008): e1000048.

11. Horimoto T., et al. "Cleavability of heamagglutinin from an extremely virulent strain of avian influenza virus containing a unique cleavage site sequence". Journal of Veterinary Medical Science 57.5 (1995): 927-930.
12. Subbarao K., et al. "Characterization of an avian influenza A (H5N1) virus isolated from a child with a fatal respiratory illness". Science 279 (1998): 393-396.

13. Zambon MC. "The pathogenesis of influenza in humans". Reviews in Medical Virology 11.4 (2001): 227-241.

14. Carrat $\mathrm{F}$ and Flahault A. "Influenza vaccine: the challenge of antigenic drift". Vaccine 25 (2007): 6852-6862.

15. Colman PM., et al. "Structure of the catalytic and antigenic sites in influenza virus neuraminidase". Nature 303.5912 (1983): 41-44.

16. Sylte MJ and Suarez DL. "Influenza Neuraminidase as a Vaccine Antigen". Current Topics in Microbiology and Immunology 333 (2009): 227-241.

\section{Assets from publication with us}

- Prompt Acknowledgement after receiving the article

- Thorough Double blinded peer review

- Rapid Publication

- Issue of Publication Certificate

- High visibility of your Published work

Website: www.actascientific.com/

Submit Article: www.actascientific.com/submission.php Email us: editor@actascientific.com

Contact us: +919182824667 